\title{
Modeling of three-phase continuously operating open-cell foam catalyst packings: sugar hydrogenation to sugar alcohols
}

\author{
Ali Najarnezhadmashhadi ${ }^{1}$, Catarina Braz ${ }^{2}$, Vincenzo Russo ${ }^{3}$, Kari Eränen ${ }^{1}$, Henrique \\ Matos $^{2}$, and Tapio Salmi ${ }^{1}$
}

${ }^{1}$ Abo Akademi

${ }^{2}$ ULISBOA

${ }^{3}$ University of Naples Federico II

December 22, 2021

\begin{abstract}
An advanced comprehensive and transient multiphase model for a trickle bed reactor with solid foam packings was developed. A new simulation model for isothermal three-phase (gas-liquid-solid) catalytic tubular reactor models was presented where axial, radial and catalyst layer effects were included. The gas, liquid and solid phase mass balances included most of the individual terms for solid foam packing (e.g. kinetics, liquid-solid and intraparticle mass transfer effects). Hydrogenation of arabinose and galactose mixture on a ruthenium catalyst supported by carbon-coated aluminum foams was applied as a fundamentally and industrially relevant case study. Parameter estimations allowed to obtain reliable and significant parameters. To test the model performance, a sensitivity analysis was performed and the effect of the kinetic parameters and the operation conditions on the arabinose and galactose conversions was studied in detail. The model described here is applicable for other three-phase continuous catalytic reactors with solid foam packings.
\end{abstract}

\section{Hosted file}

Manuscript.docx available at https://authorea.com/users/452215/articles/550334-modeling-ofthree-phase-continuously-operating-open-cell-foam-catalyst-packings-sugar-hydrogenationto-sugar-alcohols

\section{Hosted file}

Tables.docx available at https://authorea.com/users/452215/articles/550334-modeling-ofthree-phase-continuously-operating-open-cell-foam-catalyst-packings-sugar-hydrogenationto-sugar-alcohols 


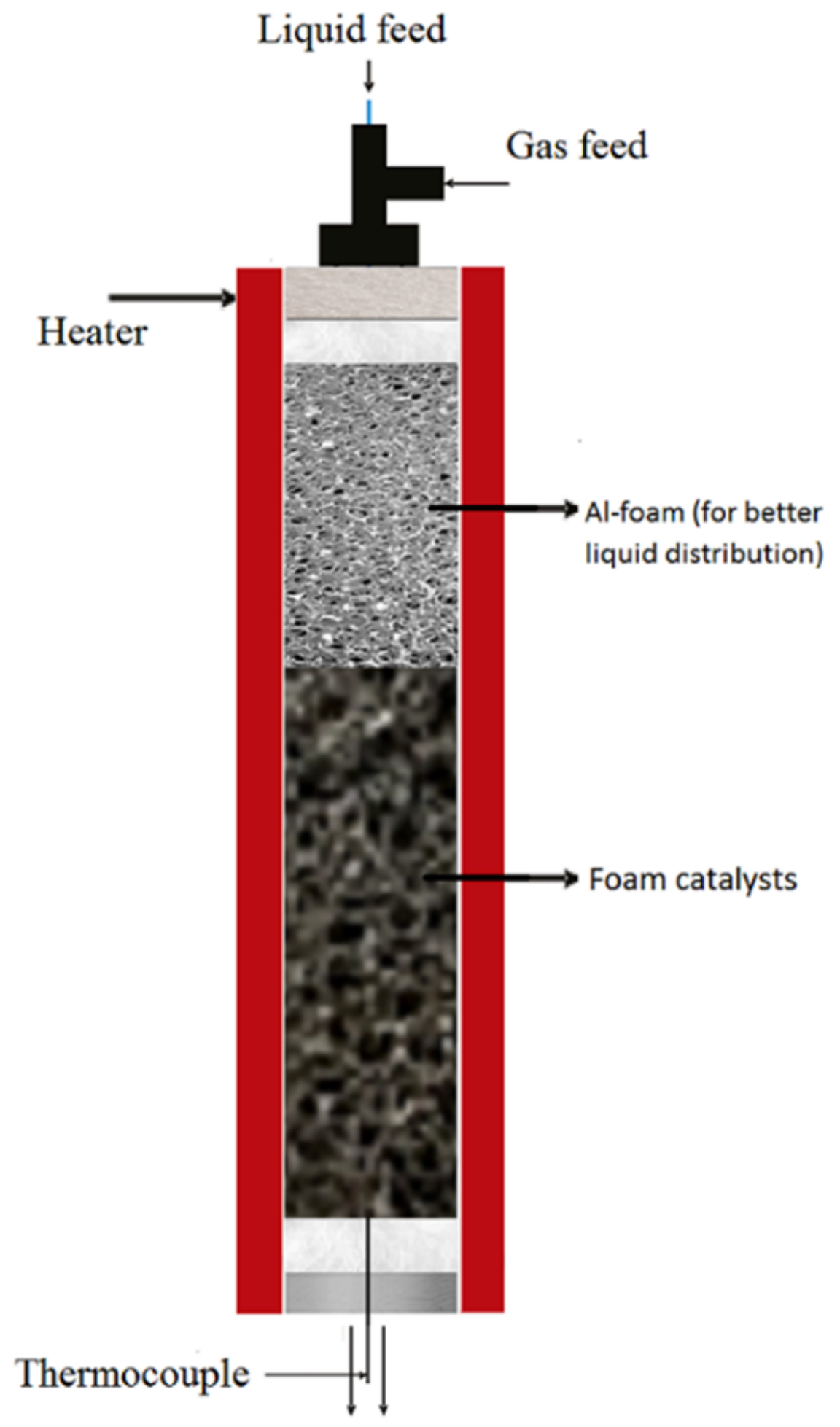



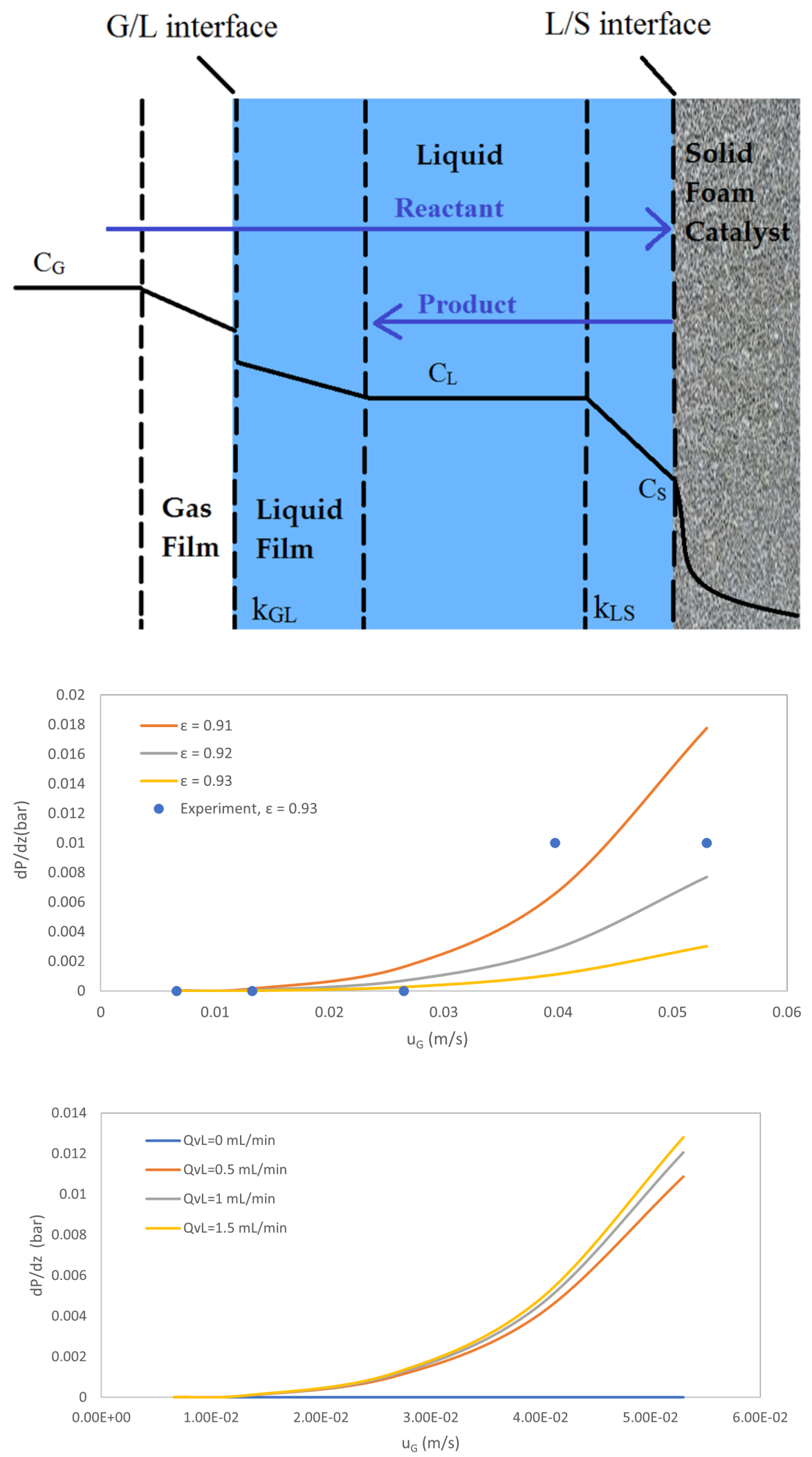

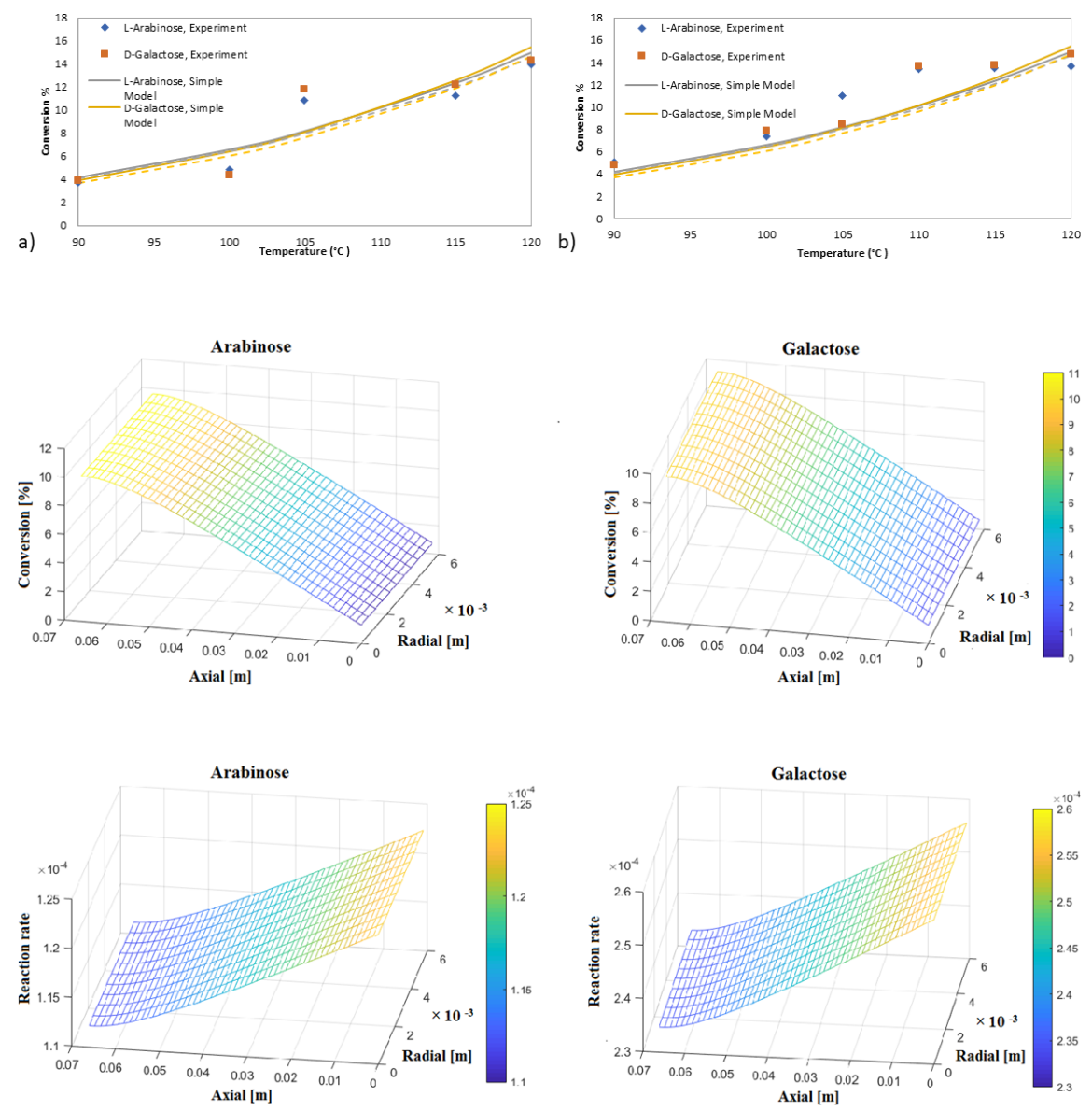

a)
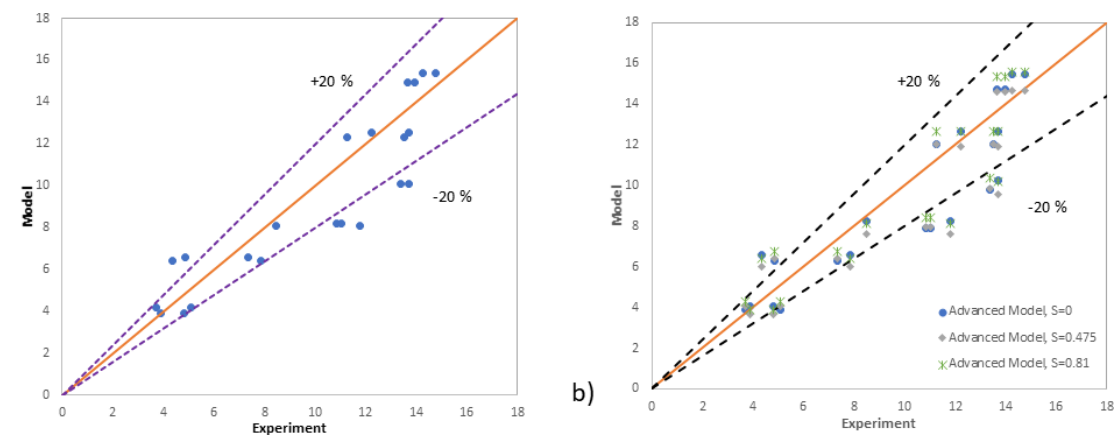

a)


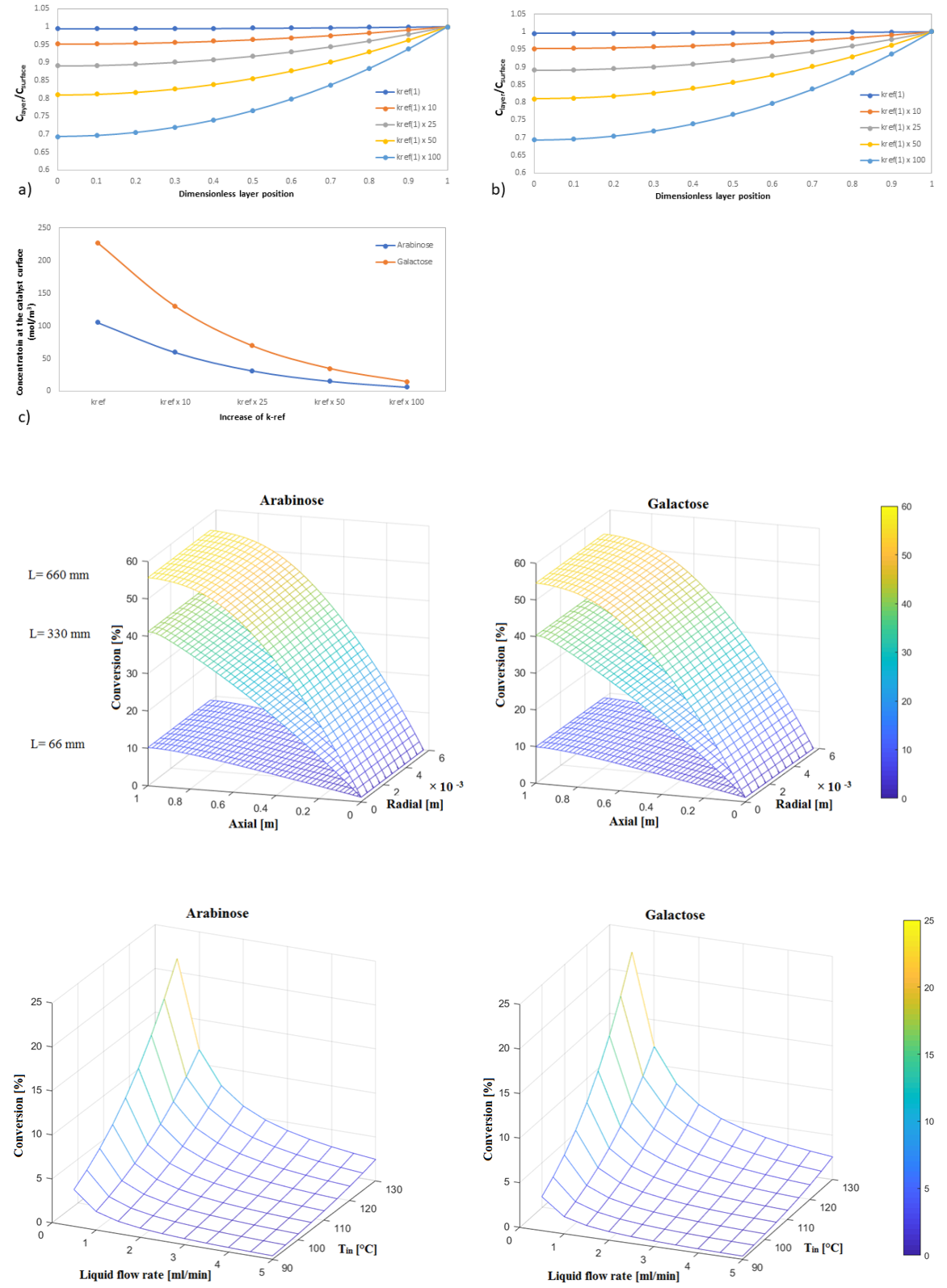


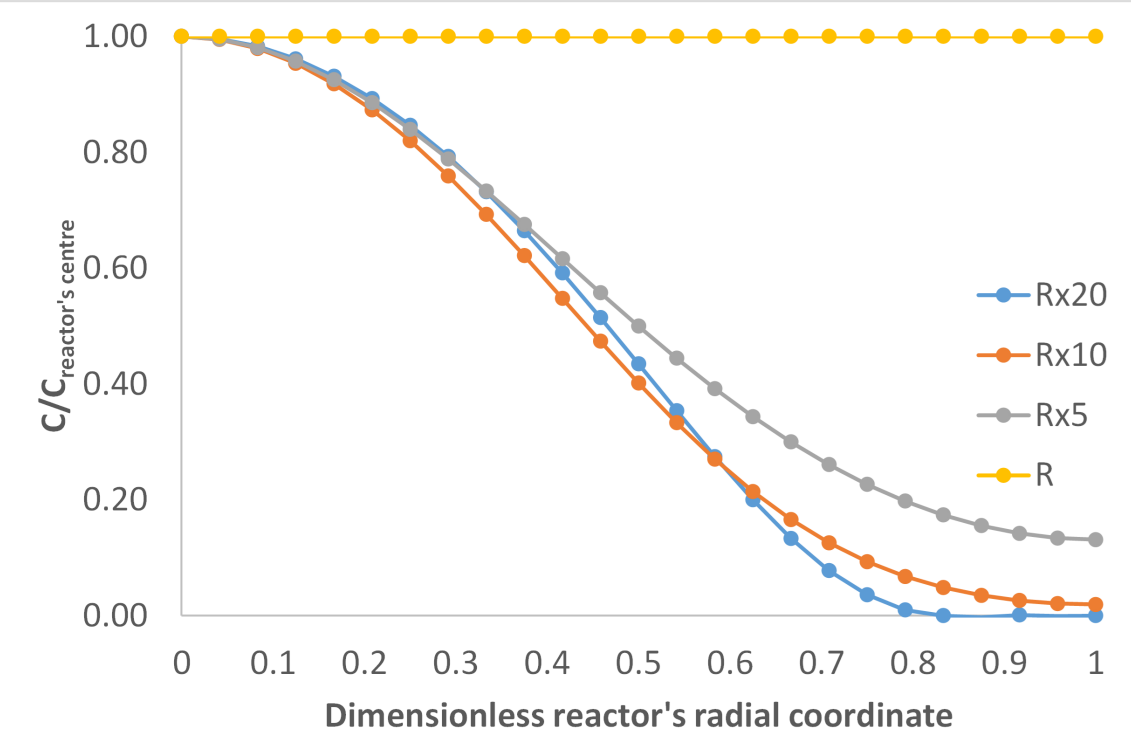

